\title{
Illk Bulgusu Cilt Tutulumu Olan Konjenital Lösemi
}

\author{
Congenital Leukemia Initially Presenting with Leukemia Cutis
}

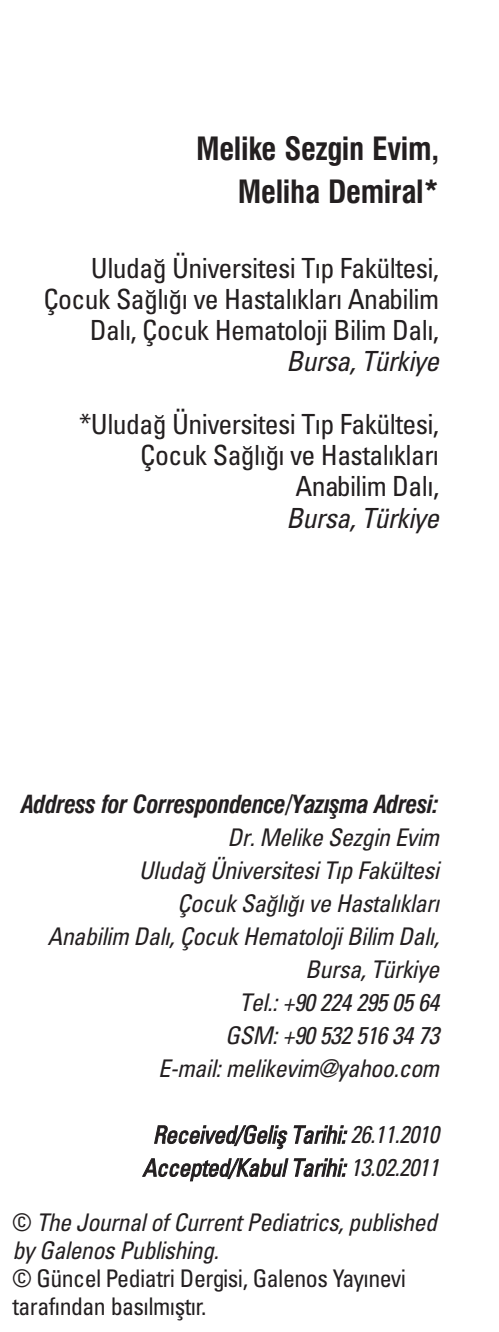

ÖZET

Giriş: Konjenital lösemi, çocukluk çağı lösemilerinin \%1'inden azını oluşturur. Prognozu kötüdür. En sık miyeloid form görülür. Olguların \%25-30'unda lösemik cilt tutulumu bulunur. 'Blueberry muffin' denilen bu lezyonlar; mavi-mor renkli, sıklıkla çok sayıda ve yaygın nodüler lezyonlardır.

Olgu Sunumu: Doğduğundan beri yaygın mavi-mor renkli nodüler lezyonları olan, sepsis düşünülerek yenidoğan ünitesinde 35 gün izlenen hasta, immün yetmezlik ön tanısı ile merkezimize yönlendirilmiştir. Fizik bakısında; soluk görünümde, tüm vücudunda yaygın, mavi-mor renkli cilt altı nodüler lezyonları ve hepatosplenomegali saptandı. Lökosit sayısı $363000 / \mathrm{mm}^{3}$ idi. Periferik kanının morfolojik ve akım sitometrisi ile değerlendirilmesi ile Akut Monositer Lösemi (AML-M5) tanısı aldı.

Tartışma: "Blueberry muffin" cilt lezyonları ile gelen hastalarda mutlaka konjenital lösemi ayırt edilmelidir. (Güncel Pediatri 2012; 10: 103-6)

Anahtar kelimeler: Konjenital lösemi, blueberry muffin lezyonu

\section{SUMMARY}

Introduction: Congenital leukemia represents less than $1 \%$ of childhood leukemia. Its prognosis is poor. Myeloid form is the most common type, and leukemia cutis has been observed in $25-30 \%$ of the patients. These skin lesions are defined as 'blueberry muffin' type which are blue-violaceous and usually multiple and diffuse nodules.

Case Report: She had diffuse blue-violaceous nodules since birth. She hospitalized due to sepsis for 35 days. She was referred to our center with the suspicion of immune deficiency. The initial physical findings were severe pallor, diffuse blue-violaceous subcutanose nodules and hepatosplenomegaly. The leucocyte count was found $363000 / \mathrm{mm}^{3}$. Acute monositer leukemia (AML-M5) was determined with morphologic and flow cytometric evaluation of the peripheral blood.

Conclusion: Congenital leukemia must be thought in differential diagnosis from other underlying disease presenting with blueberry muffin skin lesions. (Journal of Current Pediatrics 2012; 10: 103-6)

Key words: Congenital leukemia, blueberry muffin skin lesions

\section{Giriş}

Konjenital lösemi çocukluk çağının nadir görülen ve prognozu kötü bir hastalığıdır. Yenidoğan döneminde ilk bulgular yaygın mavi-mor renkli nodüler cilt lezyonları, hepatosplenomegali, solukluk olabilir. Ayrıcı tanısında konjenital viral enfeksiyonlar ve diğer malin durumlar yer alır (1-3). Bu sunuda; Uludağ Üniversitesi Tıp Fakültesi Çocuk Sağlığı ve Hastalıkları Kliniğine 55 günlük iken sepsis, immün yetmezlik ön tanıları ile yönlendirilen, ancak ayrıcı tanıda konjenital lösemi tanısı alan olgu tartışılmıştır.

\section{Olgu Sunumu}

Ondokuz yaşındaki annenin 1. gebeliğinden 1. yaşayan olarak ilerlemeyen eylem nedenli sezaryen seksiyo ile 3050 gr ağırlığında doğurtulan, antenatal döneminde özellik olmayan hasta, doğumunda tüm vücudunda yaygın morluklar olması üzerine dış bir merkezde yenidoğan ünitesinde 35 gün yatırılmıştır. $\mathrm{Bu}$ dönemde trombositopenisi ve lökositozu olan bebek neonatal sepsis, lökomoid reaksiyon olarak değerlendirilmiş ve geniş spektrumlu antibiyotik, trombosit, plazma, intravenöz immün globulin destekleri almıştır. Yapılan batın ultrasonografisinde 
karaciğer ve dalakta hipoekoik lezyonlar olması nedeniyle "hepatosplenik kandidiyazis" olabileceği düşünülerek, tedavisine antifungal (flukanazol) eklenmiştir. Lökositozu gerileyen trombosit değeri $100000 / \mathrm{mm}^{3}$ üzerine çıkan, bebek taburcu edilerek, hepatosplenik kandidiyazis ve immün yetmezlik tanıları ile ileri inceleme için Uludağ Üniversitesi Tıp Fakültesi Çocuk Sağlığı ve Hastalıkları Kliniğine yönlendirilmiștir. Hasta başvurduğunda 55 günlük idi. Fizik bakısında ağırlık: 3700 gr (3-10p), boy: $53 \mathrm{~cm}$ (1025p), baş çevresi: $40 \mathrm{~cm}$ (10p), soluk görünümde, sırt bölgesinde daha yoğun olmak üzere tüm vücudunda yaygın, mavi-mor renkli değişik boyutlarda cilt altı nodüler lezyonları vardı (Şekil 1, 2). Karaciğer kot altı 5-6 cm, dalak 4-5 cm ele geliyordu. Tam kan sayımında; lökosit 363 000/mm3, hemoglobin: $3,2 \mathrm{gr} / \mathrm{dl}$ ve trombositleri: $13000 / \mathrm{mm}^{3}$ idi. Periferik yaymada \%75 monoloblastı vardı (Şekil 3). Akım sitometride CD11c: \%85,4, CD13: \%37, CD14:\%23,3, CD15:\%52,6, CD33:\%99,6 ve i.c MP0:\%83,1 olarak saptand. Megakaryositer, eritroster ve lenfoid seriye ait markerler $\% 10$ 'nun altında bulundu. FISH analizinde \%87 oranında 11q23 pozitifliği saptandı. Olgu konjenital akut monositer lösemi (AML M5) tanısı aldı. Batın ultrasonografisinde; karaciğerde ve dalakta saptanan multiple hipoekoik lezyonların lösemik infiltrasyona bağlı olduğu düşünüldü, böbrek üstü bezi loju doğal olarak değerlendirildi. Viral serolojide özelik saptanmadı (toxoplazma IG G ve IgM negatif, sitomegalovirus, rubella, herpes için IgG pozitif, IgM: negatif, HIV taraması negatif). Olguya $2500 \mathrm{cc} / \mathrm{m}^{2}$ den $\mathrm{NaHCO}_{3}: 2 \mathrm{mg} / \mathrm{kg} / \mathrm{gün}$ içeren hidrasyon ayarlandı. PT:22 sn, PTT:31 sn ve INR:1,9 olan hastaya K vitamini yapıldı. Hastaya eritrosit ve trombosit süspansiyonu verildi. Cytarabine 75 $\mathrm{mg} / \mathrm{m}^{2}$ verildi. Yatışının 2. günü ateş yüksekliği olan hastaya

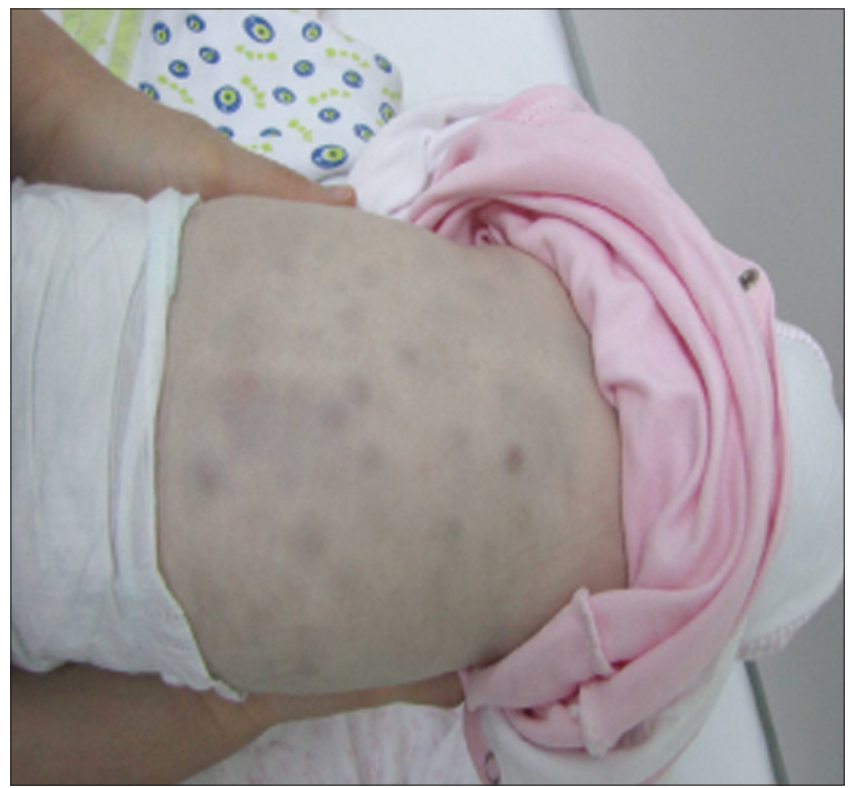

Resim 1. Hastamızın cilt lezyonlarının görünümü seftazidim ve amikasin başlandı. İleminde taşikardi ve solunum sıkıntısı gelişen, asidozu saptanan hastaya solunum desteği sağlandı. Ancak kardiak arrest gelişen hasta resusitasyona yanıt vermeyerek yatışının 3. gününde kaybedildi.

\section{Tartışma}

Konjenital lösemi nadir görülen ve prognozu kötü olan bir lösemidir. Sıklığı 4,7 milyonda bir olarak

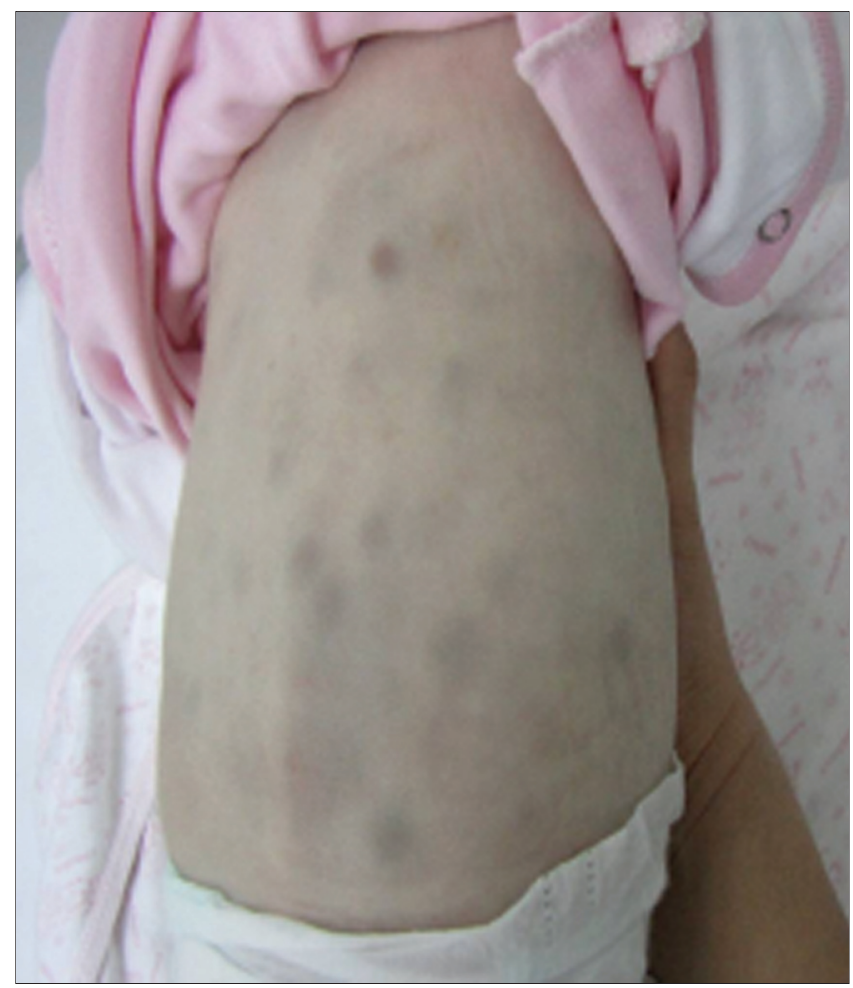

Resim 2. Hastamızın cilt lezyonlarının görünümü

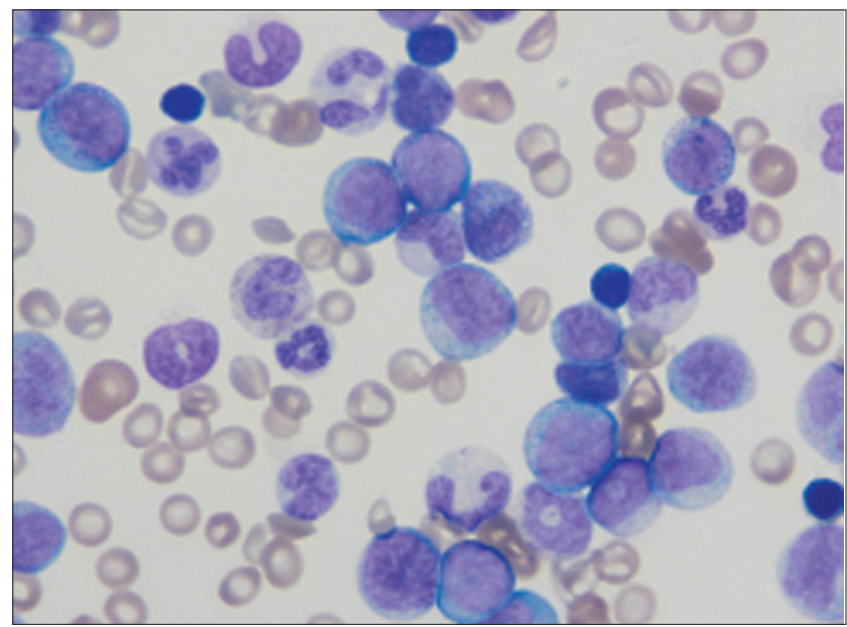

Resim 3. Periferik yayma incelemesi: x100 büyütmede monoblastlar 
bildirilmektedir (1). Tüm çocukluk çağı lösemilerinin $\% 1$ 'inden azını oluşturur. Etiyolojisi, klinik bulguları ve biyolojisi diğer çocukluk çağı lösemilerinden oldukça farklıdır. Diğer çocukluk yaş gruplarının tersine myleoid form daha sık görülür. En sık görülen AML alt tipleri ise M4 ve M5'dir (2). Konjenital löseminin klinik bulguları solukluk, hepatosplenomegali, lösemik cilt tutulumu ve tanıda yüksek lökosit sayısıdır. Lösemik cilt tutulumu vakaların \%25-30'unda görülebilir (3). Mavi-mor renkli nodüler lezyonlar, sıklıkla çok sayıda ve yaygın olarak görülür. Nadiren tek lezyon da görülebilir. 'Blueberry muffin' olarak da tanımlanan bu cilt lezyonlarının ayrıcı tanısında konjenital viral enfeksiyonlar (sitomegalovirus, toxoplazma, rubella ve diğerleri), hemolitik hastalıklar, geçici myeloprolifertaif hastalıklar ve cildi infiltre eden diğer malin durumlar (metastatik nöroblastom, Langerhans hücreli histiositozlar, malin histiositozlar) yer alır (4). Lösemik cilt tutulumunun olduğu ancak kemik iliğinin normal olduğu olgular da bildirilmiştir (5). Erişkinde görülen lösemik cilt tutulumun aksine konjenital lösemideki cilt tutulumu kötü prognoz göstergesi değildir. Konjenital löseminin tanı kriterleri: a) yaşamın ilk 4 haftası içinde başlaması b) olgun olmayan lenfoid, myeloid ve/veya eritroid hücrelerde artış olması c) hematopoetik olmayan dokularda infiltrasyon d) anormal hücre artışını açıklayacak başka bir hastalığın olmaması olarak belirtilmiştir (2).

Bizim olgumuzda da doğduğundan beri tüm vücudunda yaygın mavi-mor renkli nodüler lezyonlar bulunmakta idi. Hastanın bu dönemde olan lökositozu, trombositopenisi ve cilt bulguları neonatal sepsis ile ilişkilendirilmiş, karaciğer ultrasonografisinde yer alan lösemik infiltrasyonlar, mantar apseleri olarak değerlendirilmiştir. Hastanın cilt lezyonlarının gerilediği ve kan tablosunun toparladığı kısa bir spontan remisyon dönemi mevcuttur. Literatürde de spontan remisyona giren konjenital lösemili olgu sunumları bulunmaktadır $(5,6)$. Ayrıcı tanıya yönelik yapılan tetkiklerinde lökomoid reaksiyona neden olabilecek viral enfeksiyonlar ve sifiliz taraması negatif, nöroblastom açından yapılan batın USG'de sürrenal loj normal idi. Lökosit sayısının $100.000 / \mathrm{mm}^{3}$ üstünde olması, periferik yaymada $\% 75$ monoblast görülmesi ve akım sitometrik incelemesi ile hastamızda AML M5 tanısı düşünüldü.

Konjenital löseminin etiyolojinde annenin radyasyona ve topoizomeraz II inhibitörlerine maruziyeti (kahve, çay, kakao, şarap ve soya ürünleri), Down sendromu, Fankoni sendromu, Bloom sendromu ve nörofibromatozis yer alır (7). Diğer çocukluk çağı lösemilerinin aksine konjenital lösemide sıklıkla kromozomal anomaliler saptanır. En sık görülen kromozomal anomalisi bizim hastamızda da olduğu gibi 11q23'tür ve kötü prognozla ilişkilidir (8). Nadiren spontan remisyon bildirilmiş̧ir ve bu olguların hiç birinde 11q23 kromozomal anomalisi saptanmamışır (5). Bizim hastamızda da yapılan genetik incelemede $\% 83$ oranında 11q23 pozitifliği saptadık. MLL geni olarak adlandırıan 11q23 bölgesi hem normal hem de lösemik hücrelerdeki hematopoez için ve hücre siklusu için önemli bir gendir. Apoptozise gidişi uyarır. 11q23 bölgesindeki kırılmadan değişik genlere translokasyonlar görülmektedir ve oluşan yeni transfüzyon genleri lösemi gelişimine neden olmaktadır. Apoptozis engellenmektedir. Erken yaşta görülme, yüksek lökosit sayısı ile gelme, kötü prognoz, bifenotipik özellik gösterme, kemoterapi direnci 11q23 translokasyonlarının ortak özellikleridir. En kötü prognoz $t(1 ; 11)$ ve $t(4 ; 11)$ 'dir. MLL gen yeniden yapılanması saptanan lösemili hastaların $\% 90$ ' 6 ay ve altındaki bebeklerdir $(9,10)$.

Konjenital löseminin prognozu oldukça kötüdür. Íki yıllık sağ kalım \%23 olarak bildirilmektedir (11). Farklı tedavi protokolleri uygulanmaktadır. En sık uygulanan ilaçlar cytarabin, etoposid, daunorubicindir. Yenidoğan ve prematürelere özel doz azaltılması gereklidir $(12,13)$. Bazı merkezler ilaç toksistesi nedeniyle sadece destek tedavisi vermektedir $(14,15)$. Sepsis, ilaç toksisitesi ve hastalığın kendi biyolojisi gereği ölüm oranı yüksektir.

\section{Teşekkür}

Hastanın tanı ve takibinde yardımlarından dolayı Prof. Dr. Adalet Meral Güneş ve Doç. Dr. Birol Baytan'a teşekkür ederim.

\section{Kaynaklar}

1. Weitzman S, Grant R. Neonatal oncology: diagnostic and therapeutic dilemmas. Semin Perinatol 1997;21:102-11.

2. Resnik KS, Brod BB. Leukemia cutis in congenital leukema. Analysis and review of the world literature with report of an additional case. Arc Dermatol 1993;129:1301-6.

3. Torrelo A, Madero L, Mediero IG, Bano A, Zambrano A. Aleukemic congenital leukemia cutis. Pediatr Dermatol 2004;21:458-61.

4. Loh ML, Matthay KK. Congenital malignant disorder. In: Taeusch HW, Ballard RA, Gleason CA, editors. Avery's diseases of the newborn. 8th ed. Philadelphia: Elsevier Saunders, 2005.p.1450.

5. D'Orazio JA, Pulliam JF, Moscow JA. Spontaneous resolution of a single lesion of myeloid leukemia cutis in an infant: case report and discussion. Pediatr Hematol Oncol 2008;25:457-68.

6. Landers MC, Malempati S, Tilford D, Gatter K, White C, Schroeder TL. Spontaneous regression of aleukemia congenital leukemia cutis. Pediatr Dermatol 2005;22:26-30.

7. Bayoumy M, Wynn T, Jamil A, Kahwash S, Klopfenstein K, Ruymann F. Prenatal presentation supports the in utero development of congenital leukemia: a case report. J Pediatr Hematol Oncol 2003;25:148-52. 
8. Kaneko Y, Shikano T, Maseki N, Sakurai M, Sakurai M, Takeda $\mathrm{T}$, et al. Clinical characteristics of infant acute leukemia with or without 11q23 translocations. Leukemia 1988;2:672-6.

9. Liu H, Cheng EH, Hsieh JJ. MLL fusions: pathways to leukemia. Cancer Biol Ther 2009;8:1204-11.

10. Silverman LB. Acute lymphoblastic leukemia in infancy. Pediatr Blood Cancer. 2007; 49(Suppl 7):1070-3.

11. Bresters $D$, Reus $A C$, Veerman $A J$, van Wering $E R$, van der Does-van den Berg A, Kaspers GJ. Congenital leukaemia: the Dutch experience and review of the literature. $\mathrm{Br} \mathrm{J}$ Haematol 2002;117:513-24
12. Zhang IH, Zane LT, Braun BS, Maize $\mathrm{J} \mathrm{Jr}$, Zoger S, Loh ML.Congenital leukemia cutis with subsequent development of leukemia. J Am Acad Dermatol 2006;54(Suppl 2):22-7.

13. van Dongen JC, Dalinghaus $M$, Kroon AA, de Vries $A C$, van den Heuvel-Eibrink MM. Successful treatment of congenital acute myeloid leukemia (AML-M6) in a premature infant. $J$ Pediatr Hematol Oncol 2009;31:853-4.

14. Choi JH, Lee HB, Park CW, Lee CH. A case of congenital leukemia cutis. Ann Dermatol 2009;21:66-70.

15. Akcakus M, Patiroglu T, Deniz K, Cetin N, Ozdemir MA, Kala M. Congenital acute lymphoblastic leukemia: report of a case with leukemia cutis. Clin Pediatr 2004;43:487-90. 